\title{
Determination of Major Factors Associated with Fungal Contamination of Wheat Under Storage Conditions
}

\author{
Asela Kesho ${ }^{1,2,{ }^{*} \text {, Alemayehu Chala }}{ }^{1}$, Elfinesh Shikur ${ }^{1}$ \\ ${ }^{1}$ College of Agriculture, Hawassa University, Hawassa, Ethiopia \\ ${ }^{2}$ Ethiopian Institute of Agricultural Research, Holetta Agricultural Research Center, Addis Abeba, Ethiopia
}

Email address:

aselakesho@gmail.com (A. Kesho)

${ }^{*}$ Corresponding author

\section{To cite this article:}

Asela Kesho, Alemayehu Chala, Elfinesh Shikur. Determination of Major Factors Associated with Fungal Contamination of Wheat Under Storage Conditions. International Journal of Photochemistry and Photobiology. Vol. 3, No. 2, 2019, pp. 21-26.

doi: $10.11648 /$ j.ijpp.20190302.12

Received: October 21, 2019; Accepted: November 26, 2019; Published: December 7, 2019

\begin{abstract}
Storage fungi are among the major factors causing post-harvest deterioration of crop produce worldwide. However, their association to the major factors that contribute to fungal contamination under storage conditions remains under studied in many parts of Sub-Saharan Africa including Ethiopia. Therefore, the current work was carried out with the objectives to identify major factors that contribute to fungal contamination of wheat grains under storage conditions. For this purpose mycological analysis was carried out using 180 wheat grain samples collected from three major wheat growing zones (Arsi, West Arsi and Bale) of South East Ethiopia. Results of the mycological analysis revealed the contamination of wheat grains by fungal species at different locations and storage time with different frequencies. Fungal contamination of samples indicated that highest incidence was observed at West Arsi (96.98\%) followed by Bale (91.76\%) and Arsi (86.43\%). Fungal contamination also varied with storage period with the highest incidence of $(98.62 \%)$ followed by $(89.78 \%)$ and $(86.77 \%)$ was observed after six months, upon harvest and three months of storage, respectively. The highest fungal incidence (98.62\%) was recorded after six months storage of wheat grain. Fungal incidence was highly associated with two of the independent variables, namely, temperature and relative humidity of storage in a logistic regression model. However, there is no significant association $(\mathrm{p}<0.05)$ with grain moisture content and storage type of wheat grains under storage conditions.
\end{abstract}

Keywords: Factors, Fungal Contamination, Storage Conditions, Wheat

\section{Introduction}

\subsection{Background and Justification}

In Ethiopia, wheat is grown in different agro-ecological zones. The areas vary in-terms of weather conditions, wheat varieties grown and crop management practices. The crop contributed a great deal to the country as source of food and income but it is continuously ravaged by diseases and other biotic constraints. Among the biotic factors, fungi are the principal organisms associated with crop seeds. A complex of seed-borne fungi including the genera of Tilletia, Ustilago, Bipolaris, Fusarium, Alternaria, Drechslera, Stemphylum, Curvularia, Cladosporium, Rhizopus, Aspergillus and Penicilliumhave been reported as the most frequent seedborne fungi of wheat throughout the world [1-3]. Three genera, Fusarium, Penicilliumand Aspergillus, all potential mycotoxin producers, could be considered as the most significant toxigenic fungi growing in processed and stored foods [4]. Due to their capability to develop in a wide range of environmental conditions, fungi in the genus Aspergillus are comparatively more widespread than others [5]. Fungal growth and mycotoxin production in cereals is influenced by various factors. Climatic conditions, especially temperature and humidity, play a very important role in this process [6]. Microscopic fungi and their metabolites, mycotoxins, are often found as contaminants in agricultural products before or after harvest as well as during transportation or storage. Furthermore, infection rate of seeds depends on some environmental conditions such as high relative humidity, suitable temperature and also high level of moisture content in seed. Yield losses caused by seed-borne pathogens to 
wheat are reported between 15 to $90 \%$ of untreated seeds grown in fields [7]. It is difficult to get the exact information on post-harvest losses of grains in Ethiopia but the frequently used figure ranges from $20-30 \%$ [8].

Seed health testing to detect seed-borne pathogens is an important step in the management of crop diseases. A lot of information is available regarding the mycoflora associated with harvested wheat grains based on reports from several countries [9-11]. In Southeast Ethiopia, most of wheat production takes place in relatively cooler areas of Arsi and Bale zones followed by West Arsi zone (Shashemene and Arsi Nagelle districts). In these areas, most of the harvested wheat grains are generally stored in sacks of different sizes and quality. Wheat grains are often contaminated with many kinds of fungal agents before or after harvesting and depending on the storage conditions and prevailing environmental factors. Hence, the study of seed-borne pathogens is necessary to determine seed health status and to improve germination potential of seed, which finally leads to increase of the crop production [12]. This information is necessary for local growers to understand the seed-borne fungal pathogens infecting wheat and their frequency to make decisions on management options.

On the other hand, the diversity of the fungi, which have an implication on the management of the fungi, is not known. The development of relevant management strategies are lacking. Chemical fungicides commonly used to control growth of fungi in storage may not be appropriate in many occasions, because of their several side effects. Natural alternatives that are user friendly and demonstrate low toxicity to humans and animals should be identified. In Ethiopia, in spite of the presence of wide diversity of plants and their essential oils with antifungal properties, no or little researches have been done. Despite its importance, storage fungi has been one of the most poorly understood pathosystems in Ethiopia. So far, only limited surveys were conducted in few areas. Yield loss assessment studies have been carried out in fewer areas and they are largely based on data from field surveys. Lack of post-harvest technologies causes on an average $15-20 \%$ losses due to pests and climatic factors [13]. As a result there is a need to assess the factors associated with the incidence and frequency of storage fungi in different areas and across agro-ecological zones. Thus, this study was designed with the following objectives.

\subsection{Objectives}

To identify major factors those contribute to fungal contamination of wheat grains under storage conditions

\section{Materials and Methods}

\subsection{Sample Collection}

Wheat seed samples were collected from the major wheat growing zones (Bale, Arsi and West Arsi) of Southeastern Ethiopia from November 2017 to July 2018. Two districts per zone, three kebeles in each district and 10 households (HHs) from each kebele were selected for sample collection based on the wheat productions potential and ability to produce surplus wheat grains and save grains after harvest at least for six months. The selection of the woredas, kebeles and HHs in the three zones were facilitated by key informants composed of experts in the respective zone and woreda offices of Agricultural Development and development agents (DAs) of each kebele.

The primary samples were taken from three spots (top, middle and bottom) of each sack or store per HHs with the help of seed sampler and mixed to get composite sample. The study sample size of grains was adjusted to $1 \mathrm{Kg}$ per $\mathrm{HHs}$ and taken to laboratory of plant quarantine and seed health research program at Holeta Agricultural Research Center. There were 30 wheat samples per woreda and totally about 180 samples were collected during harvesting and at three months interval for the period of six months. The geographic coordinate's of sample collection sites (latitude, longitude and altitude) were recorded using Geographic Positioning System (GPS) unit. In addition, storage condition or type, moisture content and date of sampling were documented. Weather parameters relative humidity and temperature of storage houses were recorded by using hygrometer.

\subsection{Determination of Grain Contamination Frequency}

The percentage of grains infected (incidence) (Table 1) for each location and storage months was recorded and calculated [14].

\subsection{Determination of Independent Variables Associated to Fungal Incidence}

Summary of incidence was presented for each independent variable (Temperature, Relative Humidity, Storage Type and Moisture Content) (Table 2) and variable classes (Table 3). The association of incidence with independent variables after six month storage period was analyzed by using logistic regression with the SAS Procedure GENMOD [15-18].

\subsection{Data Analysis}

Data on fungal incidence of seed infection for samples collected from different locations of the three zones and storage months was subjected to simple descriptive analysis and data were analyzed by using the SAS computer package, version 9.3 [15]. Summary of incidence was presented for each independent variable (Temperature, Relative Humidity, Storage Type and Moisture Content) and variable classes. The association of incidence with independent variables after six month storage period was analyzed by using logistic regression with the SAS Procedure GENMOD [15-18]. Incidence of fungal infection after six months of storage was classified into distinct groups of binomial qualitative data. Thus, class boundary of $\leq 95$ and $>95 \%$ were chosen for incidence yielding a binary dependent variable.

The GENMOD procedure fits a generalized linear model to the data with a maximum likelihood estimation of the parameter. The logistic regression model allows evaluating 
the importance of multiple independent variables that affect the response variable $[19,16]$. A chi-square test is used to examine the association between two categorical variables (dependent and independent variables). The GENMOD (generalized linear models) Procedure gives parameter estimates and the standard error of the parameter estimates. Exponentiating the parameter estimate yields the odds ratio for comparing the effect based on a reference point, which is interpreted here as the relative risk [16]. The importance of the independent variables temperature of $<22^{\circ} \mathrm{C}, 22-25^{\circ} \mathrm{C}$ and $>25^{\circ} \mathrm{C}$, relative humidity of $\leq 60 \%$ and $>60 \%$, storage type of home and magazine and moisture content of $\leq 13.5 \%$ and $>13.5 \%$ was evaluated in two ways. First, the association of an independent variable alone with fungal incidence was examined. In the other method, independent variables with high association to the parameter were added to reduce multiple variable models. The odds ratio was calculated to show the strength of association between a predictor and the response of interest.

\subsection{Data Collected}

Incidence of fungi (In): Incidence of fungal infection on each sample was calculated by using the following formula:

$$
\text { In }(\%)=\frac{\text { Number of infected grains }}{\text { Total numbers of grain plated }} \times 100
$$

\section{Results and Discussions}

\subsection{Fungal Incidence Across Locations and Storage Month}

The fungal contamination of samples indicated that highest incidence was observed at West Arsi (96.98\%) followed by Bale (91.76\%) and Arsi (86.43\%), (Table 1).

White also reported as the wheat production areas in Ethiopia with the lower altitude limit is roughly 2000 m.a.s.1, the present agro-climatological constraint on wheat area is not lack of rainfall but warm temperatures. Increasing temperatures by $1{ }^{\circ} \mathrm{C}$ decreased wheat yields by $130 \mathrm{~kg} / \mathrm{ha}$, whereas an increase of $2^{\circ} \mathrm{C}$ reduced wheat yields by 270 $\mathrm{kg} / \mathrm{ha}[20]$. In terms of wheat cropping and ignoring year-to year variation, the Ethiopian highlands (to which the wheat crop is so well-adapted) represent a relatively humid environment. Growing wheat under warmer conditions might require cultivars with greater heat tolerance as well as resistance to pathogens that prevail under warmer conditions [20]. The result indicating incidence of storage fungi varied with the relative altitude, humidity, temperature and months of the storage during the study period (Table 1).

In addition fungal contamination also varied with storage period with the highest incidence of $(98.62 \%)$ followed by $(89.78 \%)$ and $(86.77 \%)$ was observed after six months, upon harvest and three months of storage, respectively (Table 1) and incidence decreased from upon harvest to the first three months of storage and then increased after the second three months of storage. Fungal contamination of stored wheat varied with storage duration and an increasing trend of percentage incidence of different fungi of wheat seeds was also recorded as the storage period prolonged from three months of storage period to six months of storage.

This result agrees with findings reported by Habib; who reported that the incidence of different groups of storage fungi boasted from the beginning of storage to the end of 180 days of storage [21]. The decreased percentage incidence of different fungi was recorded from upon harvest to the first three months of storage (after 90 days), which was resemblance with the result of Habib. Infection of fungi increased with the increase in storage time and the percentage of fungal infection start decreasing after longer storage period (after 120 days). This may be due to the exhaustion of nutrients or the accumulation of toxic metabolites produced by the fungi themselves [22]. The current study confirms similar result of previous work of Dudoiu that reported after 60 days of storage, the percent of the field fungi, respectively species of Alternaria and Cladosporium decreased, and the development of stored grain specific fungi such as Fusarium spp., Aspergillus spp. and Sclerotinia sclerotiorum. Gradually, over a storage period of 90 days, the grains' micoflora enriched by the incidence and growth of the phytopathogen fungi, due to storage conditions like high atmospheric humidity [23].

Table 1. Incidence of Fungi on Wheat Grains across Locations and Storage Months.

\begin{tabular}{|c|c|c|c|c|c|c|c|}
\hline \multirow{2}{*}{ Variable } & \multirow{2}{*}{ Variable Class } & \multirow{2}{*}{$\mathbf{N}$} & \multicolumn{3}{|c|}{ Incidence (\%) } & \multirow{2}{*}{ Std Dev } & \multirow{2}{*}{ Std Error } \\
\hline & & & Maximum & Minimum & Mean & & \\
\hline \multirow{3}{*}{ Zone } & W. Arsi & 180 & 100 & 60 & 96.98 & 7.23 & 0.54 \\
\hline & Arsi & 180 & 100 & 12 & 86.43 & 18.80 & 1.40 \\
\hline & Bale & 180 & 100 & 40 & 91.76 & 13.61 & 1.01 \\
\hline \multirow{3}{*}{ Storage month } & 0 & 180 & 100 & 12 & 89.78 & 15.89 & 1.18 \\
\hline & 3 & 180 & 100 & 12 & 86.77 & 17.33 & 1.29 \\
\hline & 6 & 180 & 100 & 74 & 98.62 & 4.19 & 0.31 \\
\hline
\end{tabular}

$\mathrm{N}$, number of samples in the three rounds; 0, period of time before storage; 3, three months after storage; 6, six months after storage; W. Arsi, West Arsi;

\subsection{Association of Fungal Incidence with Independent Variables}

Fungal incidence after six months of wheat storage in Southeast Ethiopia was significantly associated $(p<0.05)$ with two of the independent variables, namely, temperature and relative humidity of the storage in the logistic regression model (Table 2). However, there is no significant association $(p<0.05)$ with grain moisture content of $(\leq 13.5 \%$ and $>13.5 \%$ ) and storage type of wheat seed (home and magazine). 
The likelihood ratio test showed that the associations of the temperature and relative humidity of storage with fungal incidence of wheat seed after six months of storage were the highest as evidenced by higher deviance reductions and $\mathrm{x}^{2}$ value with the corresponding $\mathrm{P}$-Value $\left(\operatorname{Pr}>\mathrm{x}^{2}\right)$. These variables had significant contributions to epidemics of the storage fungi with varying levels alone or in combination. The model quantified the relative importance of independent variables implying that fungal incidence was the function of these variables, which means that some of the variables were more important causes for the decrease or increase in fungal incidence than others. However, some variables were confounded by the effect of other variables, which are important to fungal development or reduction. The model is widely applied to analyze both qualitative and quantitative data generated from different agro-ecologies, storage types, moisture condition of grains and storage conditions attributes towards fungi and mode of transmission to identify factors that promote or reduce fungal development $[24,25,18]$.

Table 2. Independent Variables Used in Logistic Regression Modeling of Fungal Incidence and Likelihood Ratio Test for Independent Variables.

\begin{tabular}{llll}
\hline \multicolumn{4}{l}{ Fungal incidence after six } \\
\hline Variable & DF & Deviance & $\mathbf{P r}>\mathbf{x}^{\mathbf{2}}$ \\
\hline Temperature & 2 & 7.93 & 0.019 \\
Relative Humidity & 1 & 5.59 & 0.018 \\
Storage Type & 1 & 0.83 & 0.363 \\
Moisture Content & 1 & 0.19 & 0.6646 \\
\hline
\end{tabular}

DF, degrees of freedom; Pr, Probability of a $x^{2}$-value exceeding the deviance; LRT, likelihood ratio test

Fungal incidence of $\leq 95 \%$ had a high probability of association to low temperature $\left(<22^{\circ} \mathrm{C}\right)$ and low relative humidity $(\leq 60 \%)$ of storage after six months of storage. On the other hand, fungal incidence of $>95 \%$ had a high probability of association to moderate temperature (22$25^{\circ} \mathrm{C}$ ). There were about four times greater probabilities that fungal incidence would exceed $95 \%$ when the temperature is moderate $\left(22^{\circ} \mathrm{C}\right.$ to $\left.25^{\circ} \mathrm{C}\right)$ as compared to high temperature $\left(>25^{\circ} \mathrm{C}\right)$. Similarly, there were about two times less probabilities that fungal incidence would exceed $95 \%$ in the both low temperature $\left(22^{\circ} \mathrm{C}\right)$ and humidity $(\leq 60 \%)$ as compared to high temperature $\left(>25^{\circ} \mathrm{C}\right)$ and humidity $(>60 \%)$ at six months of storage period. However, there were seven times lesser probabilities that fungal incidence at six months of storage would exceed $95 \%$ in the low temperature of storage as compared to mid temperature (Table 3).

Results of the current study agree Baloch, who reported that deterioration of wheat grain is closely related to the moisture content, which intron is influenced by temperature and relative humidity of the storage structure [26]. The same author also stated that at $14 \%$ moisture, wheat grain can be safely stored for 2 to 3 months, and for longer periods of storage (4-12 months) the moisture content must be reduced to $13 \%$ or below. This result is also in agreement with the result of Mannaa and Kim, who suggested that the optimum temperature for fungal growth and mycotoxin production can vary between 24 and $30^{\circ} \mathrm{C}$ depending on the fungal strain and substrate type [27].

Niaz reported that the lowest number of fungi were obtained in seeds with $8 \%$ moisture content followed by $12 \%, 16 \%$ and $20 \%$, stored at $4{ }^{\circ} \mathrm{C}$ and $25^{\circ} \mathrm{C}$, and heavy fungal infections (98$100 \%$ ) were reported on maize seed after 30 days of storage when moisture level was $20 \%$ at all temperatures $\left(25^{\circ} \mathrm{C}, 35^{\circ} \mathrm{C}\right.$ and $40^{\circ} \mathrm{C}$ ) [22]. These results suggested that the $8 \%$ moisture and $4^{\circ} \mathrm{C}, 25^{\circ} \mathrm{C}$ temperatures would be better for the storage of maize seeds to reduce the chances of mold growth and mycotoxin production. Muthomi and Narla also reported that the pathogens require humid condition for survival in the storage and also indicated that temperature and relative humidity as the two major factors influencing pathogen survival [28]. According to Conkova, fungal growth and mycotoxin production in cereals is influenced by various factors, especially temperature and humidity, play a very important role in this process [6].

Table 3. Analysis of deviance, natural logarithms of odds ratios, parameter estimate and standard error of added variables in logistic regression model analyzing fungal incidence after six months storage period of wheat seed.

\begin{tabular}{lllll}
\hline Fungal incidence after six month storage & & \\
\hline Variable $^{\mathbf{b}}$ & DF & variable classes & parameter estimate* & Standard error \\
\hline Intercept & & & 2.35 & 0.3568 \\
Temperature & 2 & $<22$ & -0.69 & 0.3935 \\
& & $22-25$ & 1.24 & 0.4392 \\
& & $>25$ & $0.00^{\mathrm{a}}$ & 0.5 \\
Relative Humidity & 1 & $\leq 60$ & -0.86 & 3.46 \\
& & $>60$ & $0.00^{\mathrm{a}}$ & 0.3637 \\
& & & 0.42 & $0.00^{\mathrm{a}}$ \\
\hline
\end{tabular}

${ }^{\mathrm{a}}$ Reference group; DF, degrees of freedom;

${ }^{b}$ Variables are added into the model in order of presentation in the table.

*Estimates are from the model with all independent variables added.

\section{Conclusion and Recommendation}

Bread wheat (Triticum aestivum L.) is one of the most important cereal crops in Ethiopia. It is widely grown in most regions of Ethiopia. However, its production is affected by abiotic and biotic factors. Among the biotic stresses, diseases caused by seed borne fungal agents or storage fungi, are among the main factors reducing yield and quality of wheat. Despite its importance, storage fungi has been one of the most poorly understood pathosystems in Ethiopia. As a result, the present study was conducted to determine major factors those contribute to fungal contamination of wheat grains under storage conditionsin major wheat growing zones to 
have a complete picture on the importance of the major factors those contribute for fungal contamination of storage wheat in the country. The major objective of the study was to contribute towards improved wheat production in Ethiopia through effective and sustainable management of storage fungi in the country.

Fungal contamination also varied with storage period with the highest incidence (98.62\%) followed by $(89.78 \%)$ and $(86.77 \%)$ was observed after six months of storage, upon harvest and three months of storage, respectively.

Understanding fungal epidemiology as affected by different variables is useful to design sustainable management strategies. The present study identified that the pathogen was influenced by temperature and relative humidity in wheat storages, and confirmed that these variables should be considered in developing management strategies against storage fungi. According to current findings, fungal contamination of wheat grains increased with storage duration and was the highest after six months of storage period. This might be due to invasion of stored grains by inocula from previously stored contaminated grains. In addition, foreign materials may restrict air movement through the grain mass leading to rise in temperature and moisture, which may favor storage mold development. High moisture content of stored grains and availability of free moisture in storage structures are also contributing factors to increased fungal infection during storage. Therefore, grains should be dried to safe moisture contents as quickly as possible after harvest, and storage structures should be well aerated to avoid excessive humidity and temperature buildup. Stored seeds and grains should also be checked on a regular basis to take necessary measures.

\section{Acknowledgements}

First of all, I would like to thank the Almighty God and St. Marry for making all things possible with their boundless and kind supply of unconditional supports. I thank my advisors Dr. Alemayehu Chala and Dr. Elfinesh Shikur, whose help from the beginning to the end of this research was substantial. Thanks are also due to my brothers and sister, Abera Kesho, who I lost this year, Asrat Kesho and Bekelech Basa.

\section{References}

[1] Hashmi F. M. H. and Ghaffar A. 2006. Seed-borne mycoflora of wheat, sorghum and barley. Pakistan Journal of Botany. 38 (1): 185-192.

[2] Rehman A., Sultana K., Minhas N., Gulfraz M., Kaukab Raja G. and Anwar Z. 2011. Study of most prevalent wheat seedborne mycoflora and its effect on seed nutritional value. African Journal of Microbiology Research. 5 (25): 4328-4337.

[3] Suproniene S., Mankeviciene A., Kadziene G., Feiziene D., Feiza V., Semaskiene R. and Dabkevicius Z. 2011. The effect of different tillage fertilization practices on the mycoflora of wheat grains. Agriculture Food Science. 20: 315-326.
[4] Essono G., Ayodele M., Akoa A., Foko J., Limbo S. and Gockowski J. 2007. Aspergillus species on cassava chips in storage in rural areas of southern Cameroon. African Journal of Microbiology Research. 1-8.

[5] Chelkowski J. 1991. Cereal grain mycotoxins, fungi and quality in drying and storage. Elsevier, Amsterdam, Netherlands. 441-476.

[6] Conkova E., Laciakova A., Styria I., Czerwiecki L. and Wilczynska G. 2006. Fungal contamination and the levels of mycotoxins (DON and OTA) in cereal samples from Poland and East Slovakia. Czech Journal of Food Science. 24 (1): 3340 .

[7] Wiese M. V. 1984. Compendium of wheat diseases. $3^{\text {rd }}$ ed. The American Phytopathological Society. 106pp.

[8] Bisrat Getnet, and Laike Kebede. 2016. Role of Mechanization in Post-harvest losses: Challenges and the way forward. Plant Protection Society of Ethiopia (PPSE) $22^{\text {nd }}$ Annual Conference. Book of Abstracts. March, 10-11, 2016.

[9] Klyszejko A., Kubus Z. and Zakowska Z. 2005. Mycological analysis of cereal samples and screening of Fusarium strains ability to form deoxynivalenole (DON) and zearalenone (ZEA) mycotoxins. Polish Journal of Microbiology. 54: 21-25.

[10] Hajihasani M., Hajihassani A. and Khaghani S. 2012. Incidence and distribution of seed-borne fungi. Journal of Biotechnology. 11 (23): 6290-6295.

[11] Bishaw Zewdie, Struik P. C. and Van Gastel A. J. G. 2013. Wheat and barley seed system in Ethiopia and Syria: farmers, varietal perceptions, seed sources and seed management. International Journal of Plant Production. 7 (4): 637-658.

[12] Dinku Senbeta and Abdella Gure. 2014. Occurrence of fungi associated with stored wheat grains (Triticumaestivum) in Shashemene and Arsi Negelle Districts, Ethiopia. International Journal of Innovation Science Research. 10: 492-497.

[13] Tadele Tefera. 2016. Post-harvest Losses in the Face of Increasing Food Shortage. Plant Protection Society of Ethiopia (PPSE) 22 $2^{\text {nd }}$ Annual Conference. Book of Abstracts. March, 10-11, 2016.

[14] Marasas W. F. O., Burgess L. W., Anelich R. Y., Lamprecht S. C. and van Schalkwyk D. J. 1988. Survey of Fusarium species associated with plant debris in South African soils. South African Journal of Botany. 54: 63-71.

[15] SAS (c). 2010. Software analyses system. Institute Inc., Cary, NC, USA version 9.3 (TS1M2 MBCS3060).

[16] Yuen J., Twengstrom E. and Sigvald R. 1996. Calibration and verification of risk algorithms using logistic regression. European Journal of Plant Pathology. 102: 847-854.

[17] Hosmer D. W. and Lemeshow S. 2000. Applied Logistic Regression. $2^{\text {nd }}$ ed. (Wiley: New York.). NY, USA.

[18] Getachew Gudero Mengesha, Habtamu Terefe Yetayew and Asela Kesho Sako. 2018. Spatial distribution and association of banana (Musa spp.) Fusarium wilts (Fusarium oxysporum $f$. $s p$. cubense) epidemics with biophysical factors in southwestern Ethiopia. Archives of Phytopathology and Plant Protection. 51 (11-12): 575-601.

[19] McCullagh P. and Nelder J. A. 1989. Generalized Linear Models. $2^{\text {nd }}$ ed. London: Chapman and Hall. $511 \mathrm{pp}$. 
[20] White J. W., Tanner D. G. and Corbett J. D. 2001. An Agroclimatological Characterization of Bread Wheat Production Areas in Ethiopia. NRG-GIS Series 01-01. Mexico. D. F. CIMMYT.

[21] Habib A., Sahi S. T., Javed N. and Ahmad S. 2011. Prevalence of seed-borne fungi on wheat during storage and its impact on seed germination. Pakistan Journal of Phytopathology. 23 (1): 42-47.

[22] Niaz I., Dawar S. and Sitara U. 2011. Effect of different moisture and storage temperature on seed borne mycoflora of maize. Pakistan Journal of Botany. 43 (5): 2639-2643.

[23] Dudoiu R., Cristea S., Lupu C., Popa D. and Oprea M. 2016. Micoflora associated with maize grains during storage period. Agrolife Scientific Journal. 5 (1): 63-58.

[24] Sahile Samuel, Chemeda Fininsa, Sakhuja P. K. and Seid Ahmed. 2008. Effect of mixed cropping and fungicides on chocolate spot (Botrytis fabae) of faba bean (Viciafaba) in Ethiopia. Crop Protection. 27: 275-282.

[25] Belete Eshetu, Amare Ayalew and Seid Ahmed. 2013. Associations of biophysical factors with faba bean root rot (Fusarium solani) epidemics in the northeastern highlands of Ethiopia. Crop Protection. 52: 39-46.

[26] Baloch U. K. 1999. Wheat: Post-harvest operations. Food Agricultural Organization United Nations, 10.

[27] Mannaa M. and Kim K. D. 2017. Influence of temperature and water activity on deleterious fungi and mycotoxin production during grain storage. Microbiology. 45 (4): 240-254.

[28] Muthomi J. W. and Narla R. D. 2015. Management of Storage Diseases in Seed Lots. Department of Plant Science and Crop Protection University of Nairobi, Kenya-Seed Enterprise Management Institutes. 